\title{
The Changing Pattern of Urethral Stricture Disease in Midwestern Nigeria
}

\author{
Dr. Temple C. Oguike Dr Vincent C. Onuorab Dr. Edwin Obarisiagbon ${ }^{c}$
}

\begin{abstract}
Sixty-eight new patients with Urethral Stricture presented at the University of Benin Teaching Hospital Benin City, Nigeria between January 1994 and December 2003, an average of seven patients per year. Fortytwo (61.9\%) of these patients were aged between 21 and 50 years, 38 (55.9\%) of the strictures were traumatic in origin and of these 23 (60.5\%) were of the bulbomembranous type and resulted from fractures of the pubic bones. Eight (21.2\%) of the traumatic strictures were from iatrogenic causes. Thirty-three (48.5\%) of the patients presented without any of the clinical complications of urethral stricture disease. Thirty-four (50.0\%) of the patients had treatments other than urethral bouginage. This picture contrasts with the situation in the past when urethral strictures were predominantly post inflammatory in origin. The patients presented more with complications, involved almost entirely bulbar or penile urethral in location and were usually treated by periodic serial dilation.
\end{abstract}

\section{INTRODUCTION}

Urethral stricture results from the fibrosis and loss of compliance of the urethra leading to bladder outlet obstruction. Urethral stricture has been a common urological condition in the sub-saharan Africal. Rapid urbanization, which is one of the legacies of the colonization of Africa, probably led to the dislocation of cultural values and so to the spread of veneral diseases the most common of which is gonococcal urethritis. Unfortunately owing to inadequate medical care most gonococcal infections were, until a few decades ago, inadequately managed. Reports from sub-

KEY WORDS: Urethral stricture, changing patterns.

${ }^{a}$ Dr. Temple C. Oguike Urology Unit, Department of Surgery University of Benin Teaching Hospital Benin. ${ }^{b} \mathrm{Dr}$ Vincent C. Onuora Urology Unit Department of Surgery UBTH. 'Dr. Edwin Obarisiagbon Urology Unit, Department of Surgery UBTH

Correspondence to: Dr. T.C. Oguike Department of Surgery UBTH, PMB 1111 Benin City. saharan Africa indicates that post inflammatory urethral stricture predominated in the sub region ${ }^{1}$. Similarly until about twenty years ago the predominant modality of treatment of urethral stricture was by repeated serial urethral bouginage, to the extent that some tertiary institutions had busy bougy clinics ${ }^{2}$.

In the past two decades however, the socio economic conditions in sub-saharan Africa has begun to change for the better. We have looked back at the urethral strictures presenting at the University of Benin Teaching Hospital in the Midwest region of Nigeria over the decade between January 1994 to December 2003. Our aim is to identify any changes in the pattern of aetiology, presentation and management of this condition in this region.

\section{Materials and Methods}

The case files of all the patients that were managed for urethral strictures at the University of Benin Teaching Hospital between January 1994 to December 2003 were retrieved from both the inpatient and outpatient

( ) CMS UNIBEN JMBR 2006; $5(2): 50-54$ 
medical records department. The biodata, aetiology of the stricture, presenting symptoms and signs, the pathological types and modalities of treatment were obtained, recorded and analysed.

\section{Results}

Sixty-eight patients with urethral stricture were managed during the 10 year period. Sixty-six (97.1\%) patients were males and $2(2.9 \%)$ were females. Their ages ranged from 11 months to 80 years. Forty-two (61.9\%) patients were of the age range between 21 and 50 years (Table 1) ; 38 (55.9\%) patients had post traumatic strictures, while 27 (39.7\%) were post inflammatory. The aetiological factor was not stated in 3 patients (Table 2). Of the patients whose strictures were of traumatic origin, $23(60.5 \%)$ were complications of fractured pelvis, $6(15.8 \%)$ from straddle injury and 2 (5.3\%) each from circumcision, repair of hypospaedia, urethral catheterisation and prostatectomy. In one patient (2.5\%) stricture resulted from Urethral injury sustained from a kick to the perineum (Table 2). On the other hand, 26 (96.3\%) of the patients with the post inflammatory strictures were from complications of gonococcal urethritis and only 1 (3.7\%) patient had a stricture at the bladder neck developing from vesical schistosamiasis (Table 2) .

Forty-two (51.7\%) patients presented with poor urinary stream, $8(11.8 \%)$ with acute retention of urine, 7 (10.3\%) with chronic urinary retention, $6(8.8 \%)$ with chronic retention with overflow incontinence, 6 (8.8\%) already had suprapubic cystostomy at presentation. Other modes of presentation were perineal urinary fistula, haematuria and scrotal swelling (Table 3) .

No clinical sign was identified in 33 (48.5\%) patients, 21 (30.9\%) had bladder distention, 8 (11.8\%) had suprapubic catheter, 2 (2.9\%) had meatal stenosis, 1 (1.5\%) each had suprapubic urinary fistula, perineal fistula, scrotal swelling or urethral induration (Table 4) .

Twenty-four (35.3\%) patients had bulbar urethral strictures, 13 (19.1\%) were located at the membranous urethra. The anatomical location of the stricture in the rest of the patients were as depicted in Table 5.

Twenty-eight (41.3\%) patients were treated with serial urethral dilation, 21 (30.8\%) with optical urethrotomy, 8 (11.8\%) had plastic repair of the urethra and $4(5.8 \%)$ by cutdown urethrotomy. One had blind urethrotomy while 5 patients had preliminary suprapubic cystostamy but defaulted from further treatment (Table 6) .

\section{Discussion}

In 1968 J.J. Shepherd reported that in some African countries, practice of Urology consisted of the treatment of urethral strictures and its complications. At this period, the vast

Table 1: Urethral Strictures in Mid West Nigeria Age Distribution

\begin{tabular}{lcl}
\hline Age (years) & Number of Patients & $\%$ \\
\hline $0-10$ & 2 & 2.94 \\
$11-12$ & 2 & 2.94 \\
$21-30$ & 18 & 26.46 \\
$31-40$ & 13 & 19.12 \\
$41-50$ & 14 & 20.58 \\
$51-60$ & 5 & 7.35 \\
$61-70$ & 6 & 8.83 \\
$71-80$ & 6 & 8.83 \\
$81-90$ & 2 & 2.94 \\
Total & 68 & 100 \\
\hline
\end{tabular}

(- CMS UNIBEN JMBR 2006; $5(2): 50-54$ 
52 Journal of Medicine and Biomedical Research

Table 2: Urethral Strictures in Midwest Nigeria Aetiology

\begin{tabular}{|l|l|l|l|l|}
\hline Predesposing Cause & Type & Number & Overall \% & Sectoral \% \\
\hline Trauma & & & & \\
& Fracture pelvis & 23 & 33.9 & 60.5 \\
& Straddle injury & 6 & 8.9 & 15.8 \\
& Circumcision & 2 & 2.9 & 5.3 \\
& Repair of Hypospaedia & 2 & 2.9 & 5.3 \\
& Urethra Catheterisation & 2 & 2.9 & 5.3 \\
& Prostatectomy & 2 & 2.9 & 5.3 \\
& Blunt trauma (football) & 1 & 1.5 & 2.5 \\
& - & 38 & 55.9 & 100 \\
\hline \multirow{5}{*}{ Total } & Infection & & & \\
& Gonococcal & 26 & 38.2 & 96.3 \\
Total & Schistosomiasis & 1 & 1.5 & 3.7 \\
\hline Unclassified & - & 27 & 39.7 & 100 \\
\hline Grand Total & - & 3 & 4.4 & - \\
\hline
\end{tabular}

Table 3: Urethral Strictures in Midwest Nigeria Presenting symptoms

\begin{tabular}{lll}
\hline Symptoms & No & \% of Total \\
\hline Poor Urinary Stream & 42 & 61.7 \\
Acute Urinary Retention & 8 & 11.8 \\
Chronic Urinary Retention & 7 & 10.3 \\
Overflow Incontinence & 6 & 8.8 \\
Suprapubic Cystostomy & 6 & 8.8 \\
Urinary Fistula & 2 & 2.9 \\
Haematuria & 2 & 2.9 \\
Swelling of Scrotum & 1 & 1.5 \\
\hline
\end{tabular}

Table 4: Urethral Strictures in Midwest Nigeria Presenting signs

\begin{tabular}{lllc}
\hline S/N & Physical Signs & No. & \% of \\
\hline 1 & None & 33 & 48.5 \\
2 & Distended Bladder & 21 & 30.9 \\
3 & Suprapubic Catheter & 8 & 11.5 \\
4 & Meatal Stenosis & 2 & 2.9 \\
5 & Suprapubic Fistula & 1 & 1.5 \\
6 & Perineal Fistula & 1 & 1.5 \\
7 & Swollen Scrotum & 1 & 1.5 \\
8 & Urethral Induration & 1 & 1.5 \\
\hline
\end{tabular}

majority of the strictures were the late complications of inadequately treated gonococcal urethritis. Indeed the incidence of traumatic strictures was negligible ${ }^{1}$.
In the last 10 years, the pattern of urethral strictures has begun to change. While post inflammatory urethral strictures predominated in the past, reports from Lagos Nigeria 
indicate that the incidence of traumatic stricture was increasing ${ }^{3}$. Similarly Aghaji and odoemene, reported that 144 urethroplasties were done at Enugu South Eastern Nigeria between 1989 and 1998 for urethral strictures, $43.8 \%$ of these strictures were post traumatic in origin ${ }^{4}$. In our study, 55.9\% of the cases had strictures of traumatic aetiology. Of the traumatic strictures in our study $60.5 \%$ were caused by fractured pelvis from road traffic accidents. The period under review had witnessed tremendous improvements in the quality of the road network in the region. Good roads encourage over speeding by vehicle drivers which can leads to severe road traffic accidents. Fractures of the pelvis often results from severe injuries to the pelvic region.

However, there is no evidence to show that the incidence of genococcal urethritis is decreasing. The decreasing proportion of post inflammatory urethral strictures is most likely due to better treatment of the infection. While underdevelopment has its own health implications, development is not without its drawbacks.

Twenty (29.4\%) patients in this study had strictures involving the membraneous urethra. In 1948 Beard and Goodyear reported that in 211 patients with urethral strictures, they could find no case in which the stricture occurred in the membranous urethra ${ }^{4}$. Similarly, Stewart (1960) stated that strictures of veneral origin stop short of about a quarter of an inch to the external sphincter ${ }^{6}$. This suggested that membranous urethral strictures are predominantly traumatic in origin. It is also pertinent to note the relatively high incidence of strictures of iatrogenic cause. In this series $26.2 \%$ of strictures resulted from procedures like circumcision, repair of hypospaedias, urethral catheteri-zation and

Table 5: Urethral Strictures in Midwest Nigeria Locations of Strictures

\begin{tabular}{llc}
\hline Type & No. & \% of Total \\
\hline Bulbar & 24 & 35.3 \\
Membranous & 13 & 19.1 \\
Bulbo-membranous & 7 & 10.3 \\
Penile & 7 & 10.3 \\
Peno-bulbar & 5 & 7.4 \\
Meatal Stenosis & 4 & 5.9 \\
Bladder neck Stenosis & 2 & 2.9 \\
Pan Urethral & 1 & 1.5 \\
Not stated & 5 & 7.4 \\
\hline Total & 68 & 100 \\
\hline
\end{tabular}

Table 6: Urethral Strictures in Midwest Nigeria Treatment Modality

\begin{tabular}{llc}
\hline Type & No. & \% of Total \\
\hline Serial Dilatation & 28 & 41.2 \\
Optical Urethrotomy & 21 & 30.8 \\
Urethroplasty & 8 & 11.8 \\
Suprapubic cystostomy & 5 & 7.4 \\
Cut down Urethrotomy & 4 & 5.8 \\
Blind Urthrotomy (Otis) & 1 & 1.5 \\
No treatment & 1 & 1.5 \\
\hline Total & 68 & 100 \\
\hline
\end{tabular}

(- CMS UNIBEN JMBR 2006; $5(2): 50-54$ 
prostatectomy. This may be a reflection of an increase in urethral surgery in modern day Nigeria. The picture of urethral stricture caused mostly by accidental and iatrogenic trauma is similar to that reported from the developed countries ${ }^{7}$.

In the past, patients frequently presented for the first time with complications of urethral strictures ${ }^{1}$. This pattern of presentation also appears to be changing as $48.5 \%$ of the patients in this series had no identifiable clinical signs resulting from complication of urethra stricture. The most frequently encountered clinical sign was mostly acute or chronic urinary retention with or without overflow incontinence. Leakage of Urine from the perineum was seen in only one patient.

This study reveals the introduction of optical urethrotomy and urethroplasty in the treatment of urethral stricture in our setting. This contrasts with the situation in the past when urethral bouginage was the mainstay in the treatment for all types of urethral strictures. For example, 83\% of the 150 urethral strictures that presented at Enugu in the eighties were treated with serial urethral bouginage ${ }^{2}$. The busy bougy clinics are no more features of our urological centres. As the quality of equipments in tertiary medical institutions and the training of specialist surgeons continue to improve, the use of bougies in the treatment of urethral strictures would become obsolete.

\section{Conclusion}

The decreasing incidence in post inflammatory urethral strictures may be due to the improving health of the people from improved treatment of urethral inflammatory diseases.
This cheering news is however dulled by the increasing incidence of post-traumatic strictures. The membranous variety of traumatic urethral strictures pose formidable surgical challenges. This calls for concerted effort to put a rein on our vehicle drivers to prevent devastating high-speed accidents that give rise to pelvic fractures. It also demands emphasis on skill acquisition in the training of specialist surgeons in the operative and instrumental management of injuries to the urethra.

\section{References}

1 Shepherd JJ, In the Companion to Surgery in Africa, edited by Davey WW \& Burkitt DP; Churchill Livingstone London 1968: 325 $-336$

2. Attah CA, Mbonu O, Anikwe RM Treatment of Urethral Stricture in University of Nigeria Teaching Hospital, Urology 1982; 20 (5) : 491494.

3. Osegbe DN Arogundade RA Changing Pattern of Urethral Stricture in Nigeria. Nigerian Postgracuate Medical Journal 1994; 1:1-5.

4 Aghaji AE Odoemene CA, One Stage Urethroplastry for Stricture: Nigerian Experience. Int J Urol 2001; 8 (7) : 380-385

5. Beard DE \& Goodyear WE, Urethral Stricture: A Pathological Study. J Urol 1948; $59: 619$

6. Stewart HH, Reconstruction of the Urethra for the treatment of severe Urethral Stricture. Br, J. Urol 1960; 32:1.

7. Smith PJ, Dunn M, Robert JBM. Surgical Management of Urethral Stricture in the Male. Urology 1981; 18: 582 - 587. 